\title{
Pseudogenization of the MCP-2/CCL8 chemokine gene in European rabbit (genus Oryctolagus), but not in species of Cottontail rabbit (Sylvilagus) and Hare (Lepus)
}

Wessel van der Loo ${ }^{1,2^{*}}$, Sandra Afonso ${ }^{1,3}$, Ana Lemos de Matos ${ }^{1,2,3}$, Joana Abrantes ${ }^{1,2,4}$ and Pedro J Esteves ${ }^{1,5}$

\begin{abstract}
Background: Recent studies in human have highlighted the importance of the monocyte chemotactic proteins (MCP) in leukocyte trafficking and their effects in inflammatory processes, tumor progression, and HIV-1 infection. In European rabbit (Oryctolagus cuniculus) one of the prime MCP targets, the chemokine receptor CCR5 underwent a unique structural alteration. Until now, no homologue of MCP-2/CCL8 $8^{\mathrm{a}}$ MCP-3/CCL7 or MCP-4/CCL13 genes have been reported for this species. This is interesting, because at least the first two genes are expressed in most, if not all, mammals studied, and appear to be implicated in a variety of important chemokine ligand-receptor interactions. By assessing the Rabbit Whole Genome Sequence (WGS) data we have searched for orthologs of the mammalian genes of the MCP-Eotaxin cluster.
\end{abstract}

Results: We have localized the orthologs of these chemokine genes in the genome of European rabbit and compared them to those of leporid genera which do (i.e. Oryctolagus and Bunolagus) or do not share the CCR5 alteration with European rabbit (i.e. Lepus and Sylvilagus). Of the Rabbit orthologs of the CCL8, CCL7, and CCL13 genes only the last two were potentially functional, although showing some structural anomalies at the protein level. The ortholog of MCP-2/CCL8 appeared to be pseudogenized by deleterious nucleotide substitutions affecting exon1 and exon2. By analyzing both genomic and cDNA products, these studies were extended to wild specimens of four genera of the Leporidae family: Oryctolagus, Bunolagus, Lepus, and Sylvilagus. It appeared that the anomalies of the MCP-3/CCL7 and MCP-4/CCL13 proteins are shared among the different species of leporids. In contrast, whereas MCP-2/CCL8 was pseudogenized in every studied specimen of the Oryctolagus - Bunolagus lineage, this gene was intact in species of the Lepus - Sylvilagus lineage, and was, at least in Lepus, correctly transcribed.

Conclusion: The biological function of a gene was often revealed in situations of dysfunction or gene loss. Infections with Myxoma virus (MYXV) tend to be fatal in European rabbit (genus Oryctolagus), while being harmless in Hares (genus Lepus) and benign in Cottontail rabbit (genus Sylvilagus), the natural hosts of the virus. This communication should stimulate research on a possible role of MCP-2/CCL8 in poxvirus related pathogenicity.

Keywords: Chemokines, Monocyte chemotactic protein, Pseudogene, Poxvirus, Myxomatosis, Oryctolagus, Bunolagus, Sylvilagus, Lepus

\footnotetext{
* Correspondence: wvdloo@mail.icav.up.pt

${ }^{1} \mathrm{CIBIO}$-UP, Centro de Investigação em Biodiversidade e Recursos Genéticos,

Campus Agrário de Vairão, Universidade do Porto, Vairão 4485-661, Portugal

Departamento de Zoologia e Antropologia, Faculdade de Ciências,

Universidade do Porto, Porto 4169-007, Portugal

Full list of author information is available at the end of the article
} 


\section{Background}

The Lagomorph family of Leporidae (leporids) originated in the New World (Neoartics/Americas), an area which still is home to the most successful of living leporids i.e. species of Sylvilagus and Lepus. The genera Sylvilagus (cottontail rabbits) and Lepus (jack rabbits or hares) comprise numerous species, with Lepus having conquered also the Old World (Paleoartics/Afro-Eurasia) [1]. In contrast, typical Old World leporid genera tend to be monotypic, inhabiting isolated areas where many of them are listed as endangered [2]. The recent world-wide success of the European rabbit (Oryctolagus cuniculus), which in prehistoric times was confined to the Southwestern parts of the Iberian Peninsula, was largely, if not entirely, due to human activity [3-6].

The introduction of Myxoma virus (MYXV) during the midst of last century as a method of rabbit pest control had devastating effects on populations of European rabbit with reported mortality rates approaching 100\% in Europe and Australia [7]. This was in sharp contrast to the very mild pathology caused by the virus in its natural host and reservoir, i.e. species of the genus Sylvilagus $[8,9]$. For Lepus species, only few cases of MYXV infections were reported and experiments in France have shown that most individuals are innately resistant, reviewed in [7]. In nature, infection with MYXV occurs through bites by flying or jumping insects. Replication of virus starts in MHC-II positive dendritic-like cells at the bite lesions and is passed on to T cells of lymph nodes draining the inoculation site [10]. The pathogenesis of MYXV infection apparently depends upon the aptitude of avoiding the spreading of infected cells throughout the lymphatic system. Whereas in cottontail rabbits MYXV infection remains localized, in 'naïve' European rabbits (below "Rabbit")", the MYXV infected cells rapidly spread to distal nodes. This results in a generalized leukocyte depletion, particular of CD4+ T cells, which leads to a systemic immunodepression with fatal outcome i.e. myxomatosis $[11,12]$.

Leukocyte migration and trafficking are mainly governed through interactions of a variety of chemokines with their cellular receptors [13,14]. Insights in the parasite strategies of immune evasion offer major gateways for identifying genetic components of pathways allowing Cottontail rabbit to cope with MYXV infection. Studies of different research teams have shown that this virus encodes a number of proteins that manipulate factors of the innate immune system of the host, among them proteins interfering directly with chemo-attractive functions of the CC chemokines $[15,16]$. It shows that these proteins have played a role during the process of coadaptation between virus and host, and most likely still do. These findings have been of cardinal guidance in the search for host genes (candidate genes) that could make the difference between susceptible vs. resistant species.
MYXV is a large double-stranded DNA virus of the poxvirus family (genus Leporipoxvirus). There have been indications that the CCR5 receptor might play a crucial role during MYXV infection, as it is the case by HIV infection in human $[17,18]$, although the experimental evidence for this has been disputed [19]. However as already mentioned, the variation of pathogenicity of the MYXV among leporid species does not depend upon the fact whether or not the virus can enter and replicate in the host cell, but more likely on a constellation of endogenous factors preventing or permitting the dissemination of infected cells throughout the lymphatic system $[11,12]$. Studies of pathways underlying the contrasting outcomes of MYXV infection may therefore contribute to a more general understanding of pathogenesis due to large DNA viruses in mammals, inclusive humans. In view of the importance of CCR2 and CCR5 receptors in HIV infection, genes controlling these receptors and their ligands might be prefigurative of such 'candidate genes'. This led to the discovery of a gene conversion that altered the second external loop of Rabbit CCR5. This mutation occurred in the ancestral lineage of the Old World genera including Oryctolagus and Bunolagus, but not in the lineages of Sylvilagus and Lepus species $[20,21]$. Although these differences at CCR5 obviously do not arbitrate the entry of MYXV for lymphocytes, they might affect CCR5 related pathways of signal transduction [17-19]. Note that Bunolagus species being highly endangered, studying their susceptibility to myxomatosis proved impracticable [2].

We therefore have taken a closer look at the main ligands of the Rabbit CCR2 and CCR5 receptors which are the 'macrophage inflammatory proteins' chemokines (MIP's) and the 'monocyte chemotactic proteins' (MCP's). The excellent recent review of the gene organization of mammalian chemokines by Nomiyama and coworkers [22], while comprehensive by extending to non-eutherian mammals (Metatheria and Monotremata), did not include Lagomorpha (Rabbits and Hares). Indeed, chemokine data on Rabbit are incomplete and sometimes erratic (see below). The Rabbit Genome Project being recently completed at the Broad Institute at 7x coverage [23], we have assessed the Rabbit Whole Genome Sequence (WGS) data for orthologs of the mammalian genes of MIP-RANTES and MCP-Eotaxin. Our analyses based on nucleotide sequence similarity revealed that Rabbit possesses proper orthologs of three MCP encoding genes (CCL7, CCL8, and CCL13) which are not identified by gene finder methods used by GenBank. The non-annotation can indicate that in Rabbit these genes may have acquired singularities hampering transcription or disqualifying them as functional proteins. We have searched for such traits and, at the event, verified their presence or absence in species of the leporid genera Oryctolagus, Bunolagus, Sylvilagus and Lepus. 
Table 1 Identification of gene structure of Rabbit CCL2,-7,-11,-8,-13,-1 genes based on Human orthologs

\begin{tabular}{|c|c|c|c|c|c|c|c|}
\hline CHEMOKINE & & & $\mathbf{P}$ & GenB & & & sense \\
\hline Species & orcu $^{\$}$ & orcu $^{\$}$ & & & Hosa ${ }^{*}$ & Hosa $^{*}$ & \\
\hline \multicolumn{8}{|l|}{ CCL2 } \\
\hline hnmRNA & 216 & 2031 & & & 227 & 2153 & \\
\hline CDS-ex1 & 287 & 362 & 0.86 & v & 300 & 375 & + \\
\hline CDS-ex2 & 1066 & 1183 & 1.00 & $v$ & 1172 & 1289 & + \\
\hline CDS-ex3 & 1534 & 1717 & 0.89 & v & 1627 & 1777 & + \\
\hline \multicolumn{8}{|l|}{ CCL7 } \\
\hline hnmRNA & 11534 & 13840 & & & 15171 & 17187 & \\
\hline CDS-ex1 & 11603 & 11678 & 0.99 & $v$ & 15241 & 15316 & + \\
\hline CDS-ex2 & 12913 & 13030 & 1.00 & - & 16096 & 16213 & + \\
\hline CDS-ex3 & 13429 & 13534 & 1.00 & - & 16647 & 16752 & + \\
\hline \multicolumn{8}{|l|}{ CCL11 } \\
\hline hnmRNA & 19375 & 22120 & & & 30618 & 33130 & \\
\hline CDS-ex1 & 19509 & 19584 & 0.89 & $-v$ & 30759 & 30834 & + \\
\hline CDS-ex2 & 20714 & 20822 & 1.00 & $\vee v$ & 32046 & 32157 & + \\
\hline CDS-ex3 & 21217 & 21322 & 1.00 & $\vee v$ & 32535 & 32640 & + \\
\hline \multicolumn{8}{|l|}{ CCL8-like } \\
\hline pseudogene & 47126 & 49449 & & & 63997 & 66352 & \\
\hline CDS-ex1 & 47576 & 47641 & & - & 64452 & 64527 & + \\
\hline CDS-ex2 & 48337 & 48455 & & - & 65219 & 65336 & + \\
\hline CDS-ex3 & 48872 & 48977 & & - & 65752 & 65857 & + \\
\hline \multicolumn{8}{|l|}{ CCL13 } \\
\hline hnmRNA & 71995 & 73927 & & & 101402 & 103560 & \\
\hline CDS-ex1 & 72083 & 72158 & 1.00 & - & 101477 & 101552 & + \\
\hline CDS-ex2 & 72902 & 73016 & 1.00 & - & 102425 & 102539 & + \\
\hline CDS-ex3 & 73361 & 73457 & 1.00 & - & 102976 & 103081 & + \\
\hline \multicolumn{8}{|l|}{ complCCL1 } \\
\hline hnmRNA & 74930 & 77383 & & & 105330 & 108183 & - \\
\hline CDS-ex3 & 75053 & 75155 & 1.00 & - & 105509 & 105611 & - \\
\hline CDS-ex2 & 76180 & 76291 & 1.00 & - & 106735 & 106846 & - \\
\hline CDS-ex1 & 77337 & 77412 & 0.91 & - & 108036 & 108111 & - \\
\hline
\end{tabular}

\$): pos 1 corresponds to position 23720000 of NC_013687.1.

*): pos 1 corresponds to position 32582070 of NC 000017.1 .

The Rabbit genome fragment R-MCPgb containing the CCL2 and CCL1 genes is compared to its Human correlate according to the alignment in Additional file 5. The identification of the Rabbit orthologs of the Human CCL genes based on sequence similarity was checked for consistency using Genscan [29], which furthermore provided estimates of the quality of intron splice sites (values varying between 0 and 1 are shown under the heading "P"). Positions of transcription initiator and termination sites were estimated by homology with Human. The exons annotated in the GenBank feature file of the Rabbit sequence (Additional file 1) are marked " $v$ " under "GenB".

\section{Results}

The genes of the CC chemokine ligands (CCL) RANTES/ CCL5, MIP-1a/CCL3, and MIP-1b/CCL4 are documented for Rabbit (Oryctolagus cuniculus) [GenBank: NC_013687_REGION:24922000..25085000]. They are located on chromosome 19 as a syntenic group [GenBank: NC_000017_REGION:34198000to34433100] and are in every respect (chromosomal location, gene organization, sequence similarity) orthologs of their mammalian counterparts $c f$. [22]. In contrast, the GenBank list of Rabbit orthologs of the mammalian MCP-Eotaxin encoding genes is limited to MCP-1/CCL2 and Eotaxin/CCL11 [Genbank: NC_013687 REGION:23720000..23798000]. True orthologs of mammalian MCP-3/CCL7, MCP$2 / C C L 8$, and MCP-4/CCL13 have not yet been identified (a print-out of the GenBank Features report is shown in Additional file 1). This is surprising because at least the first two chemokines seem to be functional 
in most, if not all mammal species studied [22], and in Human and Mouse are subject of intense investigations due to their importance in regulating inflammatory and anti-tumoral effects and for their role in HIV infection [24-28].

We will adopt the $C C L$ nomenclature unless we are dealing with proteins. For most mammals, MCP encoding genes are organized as a syntenic group composed of the chemokine genes CCL2-CCL7-CCL11-CCL8-CCL13-CCL1 [22] (in that order; $C C L 1$ serves here only as a syntenic marker). In Human the CCL2-CCL1 encompassing syntenic group is located on chromosome 17 [GenBank: NC_000017.1_ REGION:32582070..32690817]. The fragment of Rabbit chromosome 19 is homologous to this region [Genbank: NC_013687_REGION:23720000..23798000]. We will refer to it as "R-MCPgb".
The pronounced interspecies similarity between the coding sequences allowed localizing the orthologs of the CCL2, $-7,-11,-8$, and -13 genes in the Rabbit genome. The exons positions are listed side by side for Rabbit and Human in Table 1. The sequence alignments can be consulted in Additional files, with annotations for the undocumented genes (CCL7: Additional file 2, CCL8: Additional file 3, CCL13: Additional file 4) or for the entire MCPgb regions as a 'blunt' $108 \mathrm{~kb}$ alignment in FASTA format (Additional file 5).

\section{Orthologs of CCL7 and CCL13 exist and are similar among leporid species}

Of the two isoforms of the "Rabbit A11 chemokine" annotated in the GenBank, "isoform 2" is orthologous to mammalian CCL11, whereas the "isoform 1" differs

\begin{tabular}{|c|c|c|}
\hline Orcu & CCL7 WGS & $\begin{array}{c}\mid \text { Fw primer } \mid \\
\text { TATAATAGGCAGAGGCATAGCCTCCCCAGGAGCAGAGaggctgaggccagcacaggaACCTGCAGCTCTCCCTCC AAGCTCGCCTCCTC } 89\end{array}$ \\
\hline Orcu & CCL7CDNA & 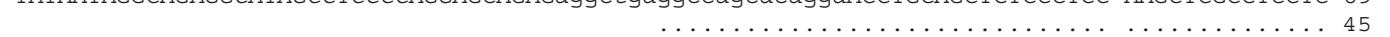 \\
\hline Leeu2 & CCL7CDNA & 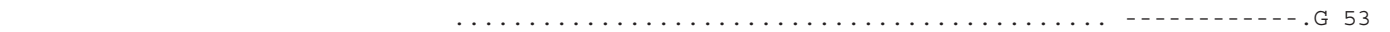 \\
\hline Legr6x & CCL7CDNA & 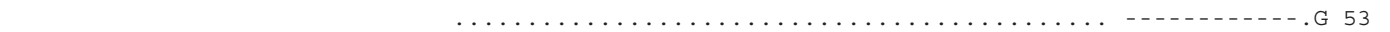 \\
\hline \multirow[t]{2}{*}{ Legr6y } & CCL7CDNA & $\ldots \ldots \ldots \ldots \ldots \ldots \ldots \ldots \ldots \ldots \ldots \ldots \ldots \ldots \ldots \ldots \ldots$ \\
\hline & & $\begin{array}{llllllllllllllllllllllllll}Q & I & S & A & A & L & L & C & L & L & L & T & V & A & A & F & S & S & Q & V & L & A & Q & P & E\end{array}$ \\
\hline Orcu & CCL7 WGS & GCGCTCCAGC ATGCAAATCTCTGCAGCACTTCTGTGCCTGCTGCTCACAGTGGCTGCCTTCAGCTCCCAGGTGCTTGCCCAGCCAGAA 177 \\
\hline Orcu & CCL7CDNA & ․․․ \\
\hline Leeu2 & CCL7CDNA & 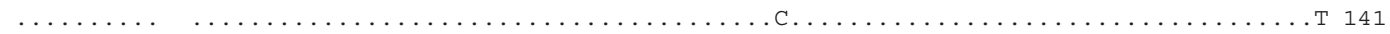 \\
\hline Legr6x & CCL7CDNA & 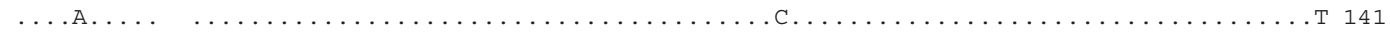 \\
\hline \multirow[t]{2}{*}{ Legr6y } & CCL7CDNA & 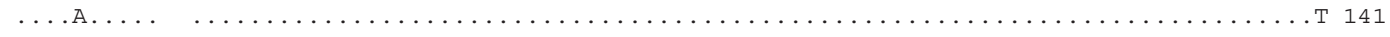 \\
\hline & & 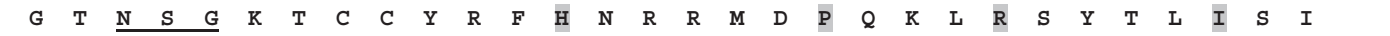 \\
\hline Orcu & CCL7 WGS & GGGACTA $\overline{A C A G C G G C A A A A C C T G C T G C T A C A G A T T C C A C A A C A G G A G G A T G G A C C C G C A G A A G C T G A G G A G C T A C A C A C T C A T C A G C A T C ~} 267$ \\
\hline Orcu & CCL7CDNA & 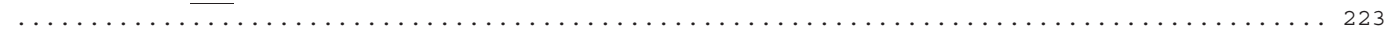 \\
\hline Leeu2 & CCL7CDNA & 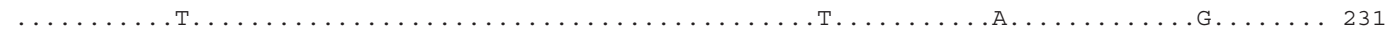 \\
\hline Legr6x & CCL7CDNA & $\ldots \ldots \ldots \ldots$ та $\ldots \ldots \ldots \ldots \ldots$. \\
\hline \multirow[t]{2}{*}{ Legr6y } & CCL7CDNA & 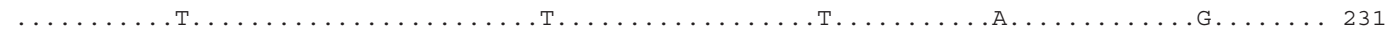 \\
\hline & & $\begin{array}{lllllllllllllllllllll}F & K & T & K & Q & H & R & E & V & C & A & D & P & K & W & P & W & A & Q & N & A\end{array}$ \\
\hline Orcu & CCL7 WGS & AGCTACTGTCCCCGGGAAGCTGTGATCTTCAAGACCAAACAGCACCGAGAGGTCTGTGCTGACCCCAAGTGGCCATGGGCCCAAAATGCC 357 \\
\hline Orcu & CCL7CDNA & 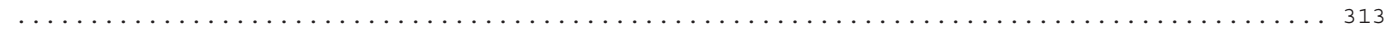 \\
\hline Leeu2 & CCL7CDNA & 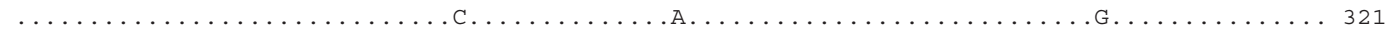 \\
\hline Legr $6 \mathrm{x}$ & CCL7CDNA & - \\
\hline \multirow[t]{2}{*}{ Legr6y } & CCL7CDNA & 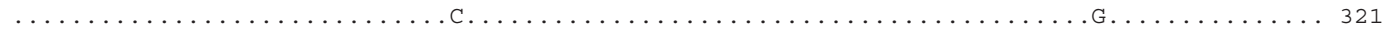 \\
\hline & & $\begin{array}{llllllllllllll}I & A & Y & L & N & K & K & T & Q & T & S & K & P & *\end{array}$ \\
\hline Orcu & CCL7 WGS & GCAGTCTTGCCTGCATTAAATCCAAGCCTGGATTTGAGAAGCAAG 444 \\
\hline Orcu & CCL7CDNA & 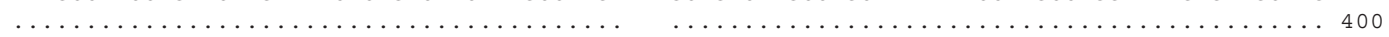 \\
\hline Leeu2 & CCL7CDNA & $\ldots \ldots \ldots \ldots \ldots \ldots \ldots \ldots \ldots \ldots \ldots \ldots \ldots$ \\
\hline Legr $6 \mathrm{x}$ & CCL7CDNA & $\ldots \ldots \ldots \ldots \ldots \ldots \ldots \ldots \ldots \ldots \ldots \ldots \ldots$ \\
\hline Legr6y & CCL7CDNA & $\ldots \ldots \ldots \ldots \ldots \ldots \ldots \ldots \ldots \ldots \ldots \ldots$ A 408 \\
\hline Orcu & CCL7 WGS & TAACCTGTGTCCACTCGCTTCAACTCAAGAGTTGTGCAGAGATTATCTTGTTGTAATTCTAAGAAATAGGAGCTTTGTGTAGTCGTGTGA 534 \\
\hline Orcu & CCL7CDNA & 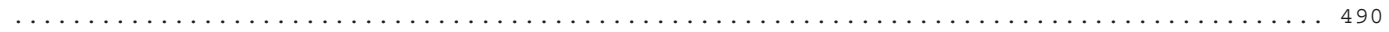 \\
\hline Legr $6 \mathrm{x}$ & CCL7CDNA & 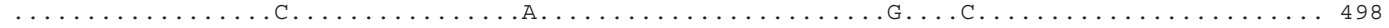 \\
\hline \multirow[t]{2}{*}{ Legr6y } & CCL7CDNA & 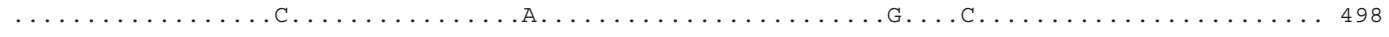 \\
\hline & & primer \\
\hline Orcu & CCL7 WGS & АTСАСАGTTTTCCTTAAATATTTTTAAGTTATTAGCACСTTAATTTAACTTGCACTGGCATGGGGGAGGA 604 \\
\hline Orcu & CCL7CDNA & 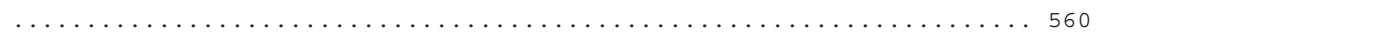 \\
\hline Legr $6 \mathrm{x}$ & CCL7CDNA & 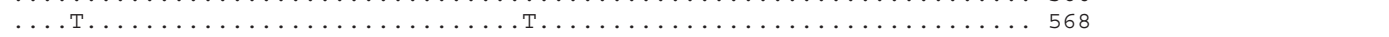 \\
\hline Legr6y & CCL7CDNA & 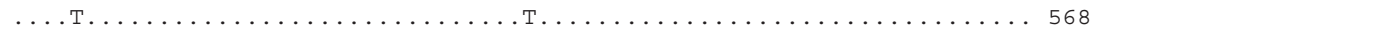 \\
\hline \multicolumn{3}{|c|}{$\begin{array}{l}\text { Figure } 1 \text { The rabbit ortholog of human CCL7 gene exists and is transcribed. The "A11 isoform } 1 \text { " predicted by GenBank suggests that exon } 1 \\
\text { of the Rabbit ortholog of CCL7 uses preferentially exon2 and exon3 of CCL11 during transcription (Additional file } 2 \text { ). We show that CDNA of the } \\
\text { leporid species (Oryctolagus cuniculus, Lepus granatensis and Lepus europaeus) contain a transcript uniting three exons orthologous to those of } \\
\text { human CCL7 gene. The position of missing MCP-3 characteristic N-glycosylation site is underlined ( } \mathrm{N} X \mathrm{~S} \text { in other mammals). Variable amino acid } \\
\text { residues are highlighted in gray. }\end{array}$} \\
\hline
\end{tabular}




\begin{tabular}{|c|c|}
\hline & 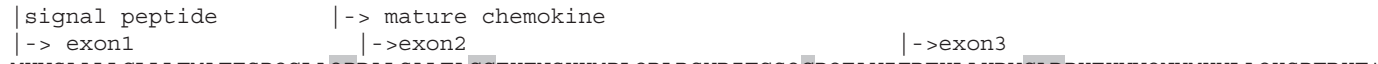 \\
\hline CCL13 eqCa mRNA & MKVSAALLCLLLTMATFSPQGLAQPDALSALTACCFKFNSKKMPLQRLRSYRITGSQCPQEAVIFRTKLAKDVCADPKEKWVQNYMKYLAQKSPTRKT * \\
\hline CCL13Calu mRNA & 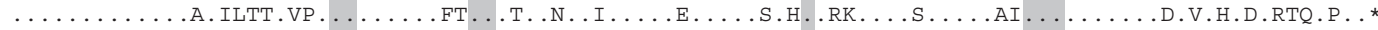 \\
\hline CCL13hosa mRNA & 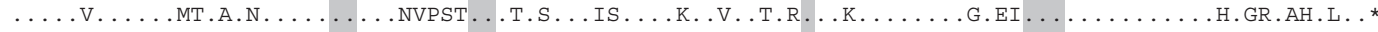 \\
\hline CCL13poab mRNA & 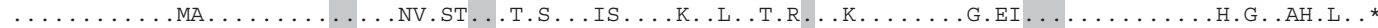 \\
\hline CCL13patr mRNA & 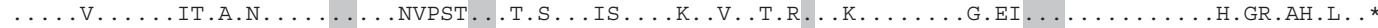 \\
\hline CCL13mamu MRNA & $\ldots \ldots$. \\
\hline CCL13aime mRNA & 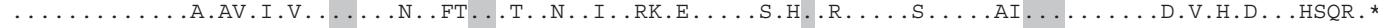 \\
\hline OrCUENSOCU13408 & 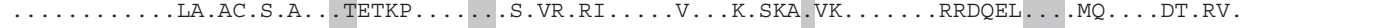 \\
\hline CCL13orCUWGSgDNA & 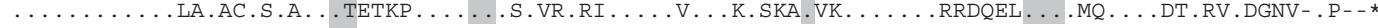 \\
\hline CCL130rCUB gDNA & ... W LA.AC.S.A..T \\
\hline CCL130ICUA GDNA & . W W LA.AC.S.A. .T \\
\hline CCL13syfl1 gDNA & .......LA.AC.S.A..T \\
\hline CCL13syfl2 gDNA & 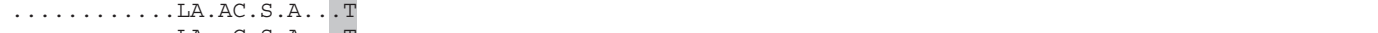 \\
\hline$C C L 13 \operatorname{Legr1}$ gDNA & . LA. .C.S.A...T \\
\hline \multicolumn{2}{|c|}{$\begin{array}{l}\text { Figure } 2 \text { Lacking of N-terminal X-Pro motifs in Leporid MCP-4/CCL13. All known MCP genes encode a } 24 G I n P r o 25 \text { (QP) motif which is } \\
\text { required for post-transcriptional maturation and modification of the protein. The Rabbit CCL13 ortholog is unique by encoding a } 24 G I n T h r 25 \\
\text { motif (QT). This particularity appears to be shared among leporids, inclusive Sylvilagus. Leporid genomic DNA was amplified using CCL13 primers } \\
\text { designed on R-MCPgb. orcuB: Rabbit, subsp. cuniculus, orcuA: Rabbit, subsp. algirus, syfl: Western Cottontail Rabbit, Legr: Granada Hare, OrCu } \\
\text { ENS13408: [Ensembl: ENSOCUT00000013408]. The MCP-4 protein sequences of "other" mammals are derived from the CCL13 mRNA sequences } \\
\text { listed in Additional file 9. eqca: horse, calu: dog, hosa: human, poab: orangutan, mamu: monkey, aime: giant panda. }\end{array}$} \\
\hline
\end{tabular}

from CCL11 only by using as initiating exon a sequence located upstream between CCL2 and CCL11. Sequence alignments make it clear that this exon is orthologous to the initiating exon of mammalian CCL7 and at the same time reveal potential exons that are orthologs of the mammalian CCL7 exons 2 and 3. The mRNA transcripts of both CCL11 isoforms are also reported as 'transcriptional variants 2' [GenBank: XM_002719227.1] and 'transcriptional variant 1' [GenBank: XM_002719226.1].

We have evaluated the putative functionality of the CCL7, -11, and -13 genes, by submitting the R-MCP fragment to Gene Finder software, which did report three exons for each of five genes (CCL2, -7, -11, -13, and -1). All exons were localized exactly as previously inferred by sequence similarity (Table 1 ). The predicted genes were confirmed by testing specimens of Oryctolagus and Lepus for correct transcription of the CCL7 gene by PCR amplification of cDNA. The CCL7 gene appeared to be transcribed as predicted in Table 1 (Figure 1). Although they are not identified as such, Ensembl.org reports a Rabbit sequence [Ensembl: ENSOCUG00000013412] and its translation [Ensembl: ENSOCUT00000013408] which correspond to transcripts of the CCL13 ortholog as defined in Table 1 (Figure 2; for detailed descriptions see Additional file 6). The fact this sequence was derived from cDNA implies that also the CCL13 gene is transcribed. We note the minor sequencing differences at the 3 ' end of the sequence which might have to do with proximity of the reverse primer used for cDNA amplification.

Transcription alone does not necessarily warrant a functional gene product. The proteins deduced from Rabbit CCL7/MCP-3 and CCL13/MCP-4 CDS sequences show indeed structural anomalies which could disqualify them as functional MCP chemokines. Rabbit MCP-3/CCL7 misses an N-glycosylation site which is present in all known MCP-3 sequences [30]. As glycosylation of MCP-3 may affect its biological activity [31], the loss of the AsnXSer site (underlined in Figure 1) might impair normal chemokine function.

The situation is more problematic with MCP-4/ CCL13. Mature MCP chemokines are derived from the precursor sequence after cyclization of the glutamine Gln24 residue, which is encoded by the 3' end of exon1. In reports on the biological activity of MCP's, the resulting N-terminal pyroglutamic acid (pGlu) is therefore referred to as pGlu1 rather than Gln24. Indeed, most reported MCP protein precursors (CCL2, -7, -8, and -13) are characterized by a 24 GlnPro 25 motif which after cyclization can further be modified by different types of metalloproteinases [32-34]. At the same time, pGlu blocks the action of serine protease peptidases, which in non-MCP chemokines recognize the ubiquitous Pro residue at position 2 of the $\mathrm{NH}_{2}$-terminus of the mature protein, by this way fine tuning their function [24,35]. The MCP-4/CCL13 precursor protein inferred from the R-MCPgb sequence is particular by showing a 24GlnThr25 motif instead of the canonical $24 G \ln$ Pro25. Whereas a Gln24 residue is not a prerequisite of chemokine maturation (e.g. in Rodent MCP2/CCL8 and Human Eotaxin/CCL11 it is replaced by Gly), the absence of a 24X-Pro25 motif is liable to prevent normal posttranslational processing.

However, we found by PCR of gDNA that these singularities encoded by the Rabbit CCL7 and CCL13 genes are shared among the different leporid genera studied, including Sylvilagus (Figures 1 and 2), making a contribution to species-specific variation in disease resistance highly unlikely.

Interestingly, the two Ensembl ENSOCU sequences mentioned were either designated as RABIT CCL8 or as Rabbit CCL7 (Additional file 6). The confusion about 


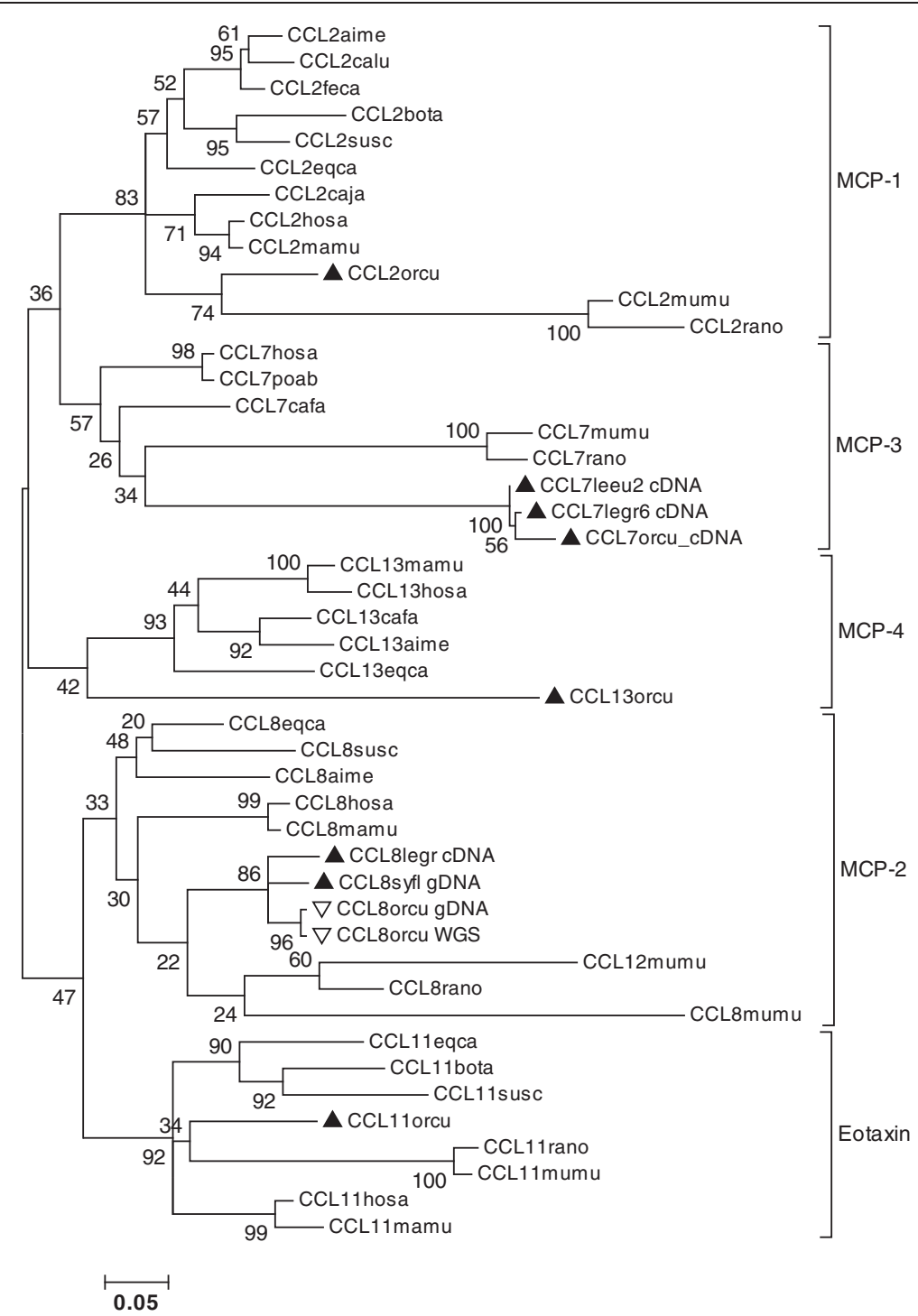

Figure 3 Gene orthology of CCL2, $-7,-11,-8$, and -13 of placental mammals supported by phylogeny. The evolutionary history was inferred by using the Maximum Likelihood method conducted in MEGA5 [36]. The tree with the highest log likelihood (-4585.9908) is shown. Bootstrap values are placed next to the branches. Codon positions included were $1^{\text {st }}+2^{\text {nd }}+3^{\text {rd }}$ and were limited to those encoding the mature chemokine. There were 231 positions in the final data set. Positions of leporid branches are highlighted by triangles $\boldsymbol{\Lambda}$ for functional, or by $\nabla$ for pseudogenes. Taxon names of sequences obtained in this study are extended by 'gDNA' when derived from genomic DNA or by 'CDNA' when (also) derived from CDNA. All other sequences represent a sample of mRNA sequences listed in Additional file 9. Mouse CCL12 and CCL8 are located between the CCL11 and CCL1 genes and are likely duplicates of the ortholog of murid CCL8 [22].

identifying the Rabbit CCL13 and CCL7 orthologs is probably due to the relatively large protein distances separating them from their mammalian correlates (Figure 2). Different methods of phylogenetic reconstruction produced nevertheless trees in which the paralogous genes did cluster according to orthology, inclusive the Rabbit genes (Figure 3). Bootstrap values were however very low. Incidentally, the branch lengths of Rabbit CCL7 and - 13 nodes were about two times larger in comparison to the average branch length of the
Rabbit CCL2, -8 , and -11 nodes. Note that Leporid CCL8 is relatively well conserved (Figure 3 ).

We conclude that Leporid orthologs of CCL7 and CCL13 exist and are transcribed but that their contribution to species-specific disease resistance is unlikely.

\section{The Rabbit ortholog of CCL8 exists but is pseudogenized}

Sequence alignments of mammalian CCL8 mRNA (at least for swine, horse, cow, panda, human and dolphin) identify clearly a single region of outstanding CCL8 


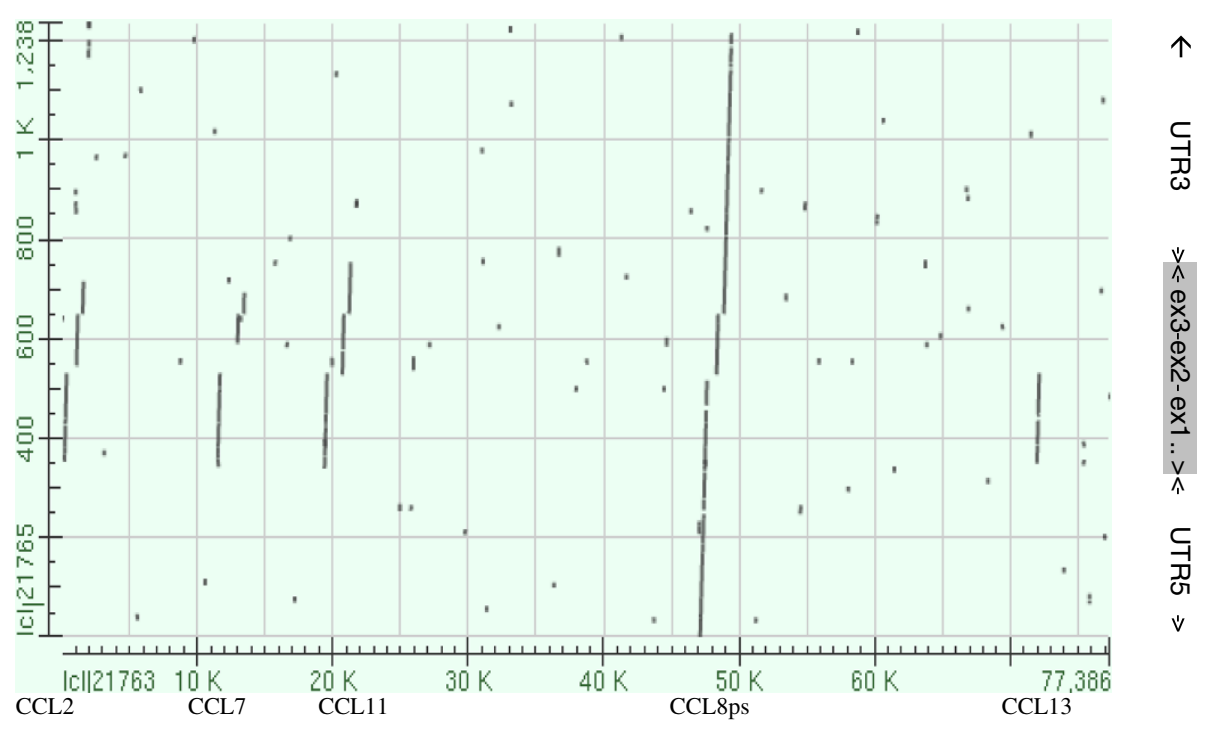

$\begin{array}{lll}\text { Y as - subject: } & \text { Human_CCL8 mRNA, } & \text { NM_005623, } 1241 \mathrm{bp} \\ \mathrm{X} \text { as - query: } & \text { Rabbit_MPCgb gDNA, } & \text { NC_013687: 23720000..23798000, 78001bp }\end{array}$

Figure 4 Fishing the Rabbit CCL8 ortholog using NCBI Blast-Align. Human CCL8 mRNA is compared to the Rabbit genomic fragment containing both the CCL2 and the CCL1 region (R-MCPgb). The graphical representation visualizes the outstanding similarity of one genomic region covering the human RNA transcript almost entirely. At the same time it localizes other structurally related regions and reveals that compared to the coding regions, untranslated region (UTR's) might be more gene-specific. The graph was produced using the online facilities offered by NCBI (http://blast.ncbi.nlm.nih.gov/Blast.cgi; option: Align).

homology within R-MCPgb. It is located between the CCL11 and CCL13 genes, as is the case for CCL8 in most, if not all mammals for which this has been checked [22]. It is interesting that gene orthology was much better revealed when the untranslated regions (UTR's) were included. This is illustrated in Figure 4. Whereas the coding regions of CCL8 show pronounced cross-paralog similarity with at least CCL2, -7 , and -11 , the UTR's are highly gene specific.

The comparison of the Rabbit CCL 8 sequence with its mammalian counterparts (Figure 5) reveals several deleterious mutations at exon1 and exon2, as well as at intron2. At exon1 the initiating methionine codon (ATG) was mutated into an isoleucine codon (ATA) and the CAG codon of the canonical GlnPro motif (CAG.CCA) at the 3' end of the exon was changed into TAG. This premature stop codon is however put out of frame by a 10 base pair (bp) deletion, which incidentally transforms the in-frame LeuSer codons (CTG.AGC) into a premature stop codon (c.TGA.gc). The 3' part of exon2 is corrupted by a 1 bp insert, while the GT donor site of intron 2 is mutated into AT. In addition, the codon of the third of the four characteristic cysteine residues (TGT) was altered into arginine (CGT), or histidine (CAT) in some wild rabbits (Figure 6). At this position, a cysteine residue is mandatory for the formation of a disulfide bound with the first cysteine of the characteristic cysteine pair [37] and present in all CC chemokines.
A first question was in how far the WGS CCL8 sequence is representative of the species, and if so, whether this situation is limited to the genus Oryctolagus. In order to assess the distribution and history of this apparent gene loss, we designed primers for each exon of the Rabbit CCL8 ortholog (see Methods). By PCR we obtained the CCL8 pseudogene (CCL8ps) DNA sequences of wild rabbits of both subspecies Oryctolagus c. cuniculus and Oryctolagus c. algirus. These rabbits were collected in the original distribution range of the genus (i.e. the Iberian Peninsula), where the gene diversity is much greater than in domestic and wild rabbits of the more recent areas of Rabbit colonization $[38,39]$. The PCR products confirmed that the CCL8 ortholog is pseudogenized in all Rabbit genomes studied. Individual variation was observed. Only one rabbit showed a sequence identical with the CCL8 sequence of R-MCPgb. It is interesting that for a majority of wild rabbits, the CCL8 genes appeared as "less" derived compared to the Thorbecke rabbit of the WGS files (Figure 6). While all genomes studied showed the initiation site mutation ATG->ATA, many of them did not show the 10 bp deletion at exon1, and the vast majority did feature the canonic 24GlnPro25 codons instead of the in-frame stop codon of the WGS sequence. Moreover they disposed of one or even two Met(ATG) inframe codons, which could possibly provide a rescue initiation site (Figure 6). 


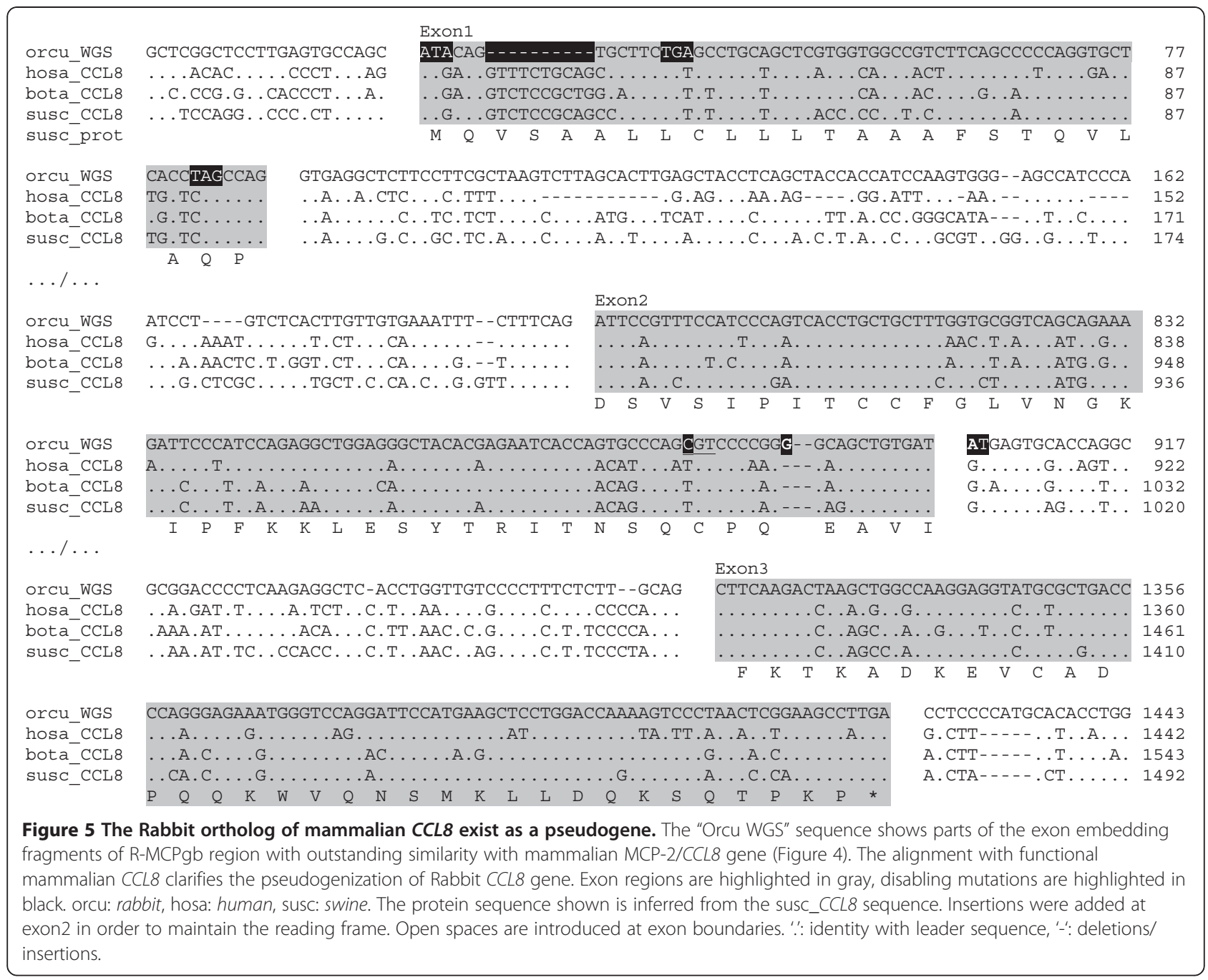

The situation is more clear-cut at exon2. The three deleterious mutations were present in all Rabbit haplotypes: (1) the altered third mandatory cysteine codon, (2) the $1 \mathrm{bp}$ insert, and (3) the donor site alteration. On the other hand, at least two genomes showed the loss of the characteristic CysCys motif of exon2 (TGCTGC-> TGCTCC), a deleterious mutation not present in the WGS Rabbit. The alignment with wild rabbit sequences furthermore revealed an interesting $33 \mathrm{bp}$ insertion in the WGS sequences, which went unnoticed in previous alignments with non-leporid sequences (Figure 5). This insert was present in both subspecies, although not in all specimens. It results from an exact direct repeat at the junction exon2-intron2, spanning the $1 \mathrm{bp}$ insert and the donor site mutation. Because both of these disabling mutations were present in all rabbit haplotypes, and repeated in the insert, the duplication is most likely more recent. This also applies to the $10 \mathrm{bp}$ deletion at exon1 (you can't delete nor duplicate what didn't already exist). It indicates that the latter are consequences of a prior loss of functionality, and are part of a process of pseudogenization.

The terminating exon3 was found to be potentially "functional" in all rabbits studied.

\section{The Rabbit CCL8 has been pseudogenized for more than 4 million years}

These deleterious mutations are shared among both Rabbit subspecies O. c. cuniculus and O. c. algirus. These subspecies did separate about 2 My ago [40,41], implying that the pseudogenization of CCL8 must be relatively old and possibly older than the genus. This was corroborated by the CCL8 sequence obtained with one Riverine Rabbit, Bunolagus monticularis, which showed all four deleterious mutations shared among Oryctolagus. The pseudogenization must precede the genus split of Bunolagus and Oryctolagus which occurred an estimated 4 My ago [40,42].

We note in both haplotypes of the Bunolagus specimen the absence of the $10 \mathrm{bp}$ deletion at the 5 region of 


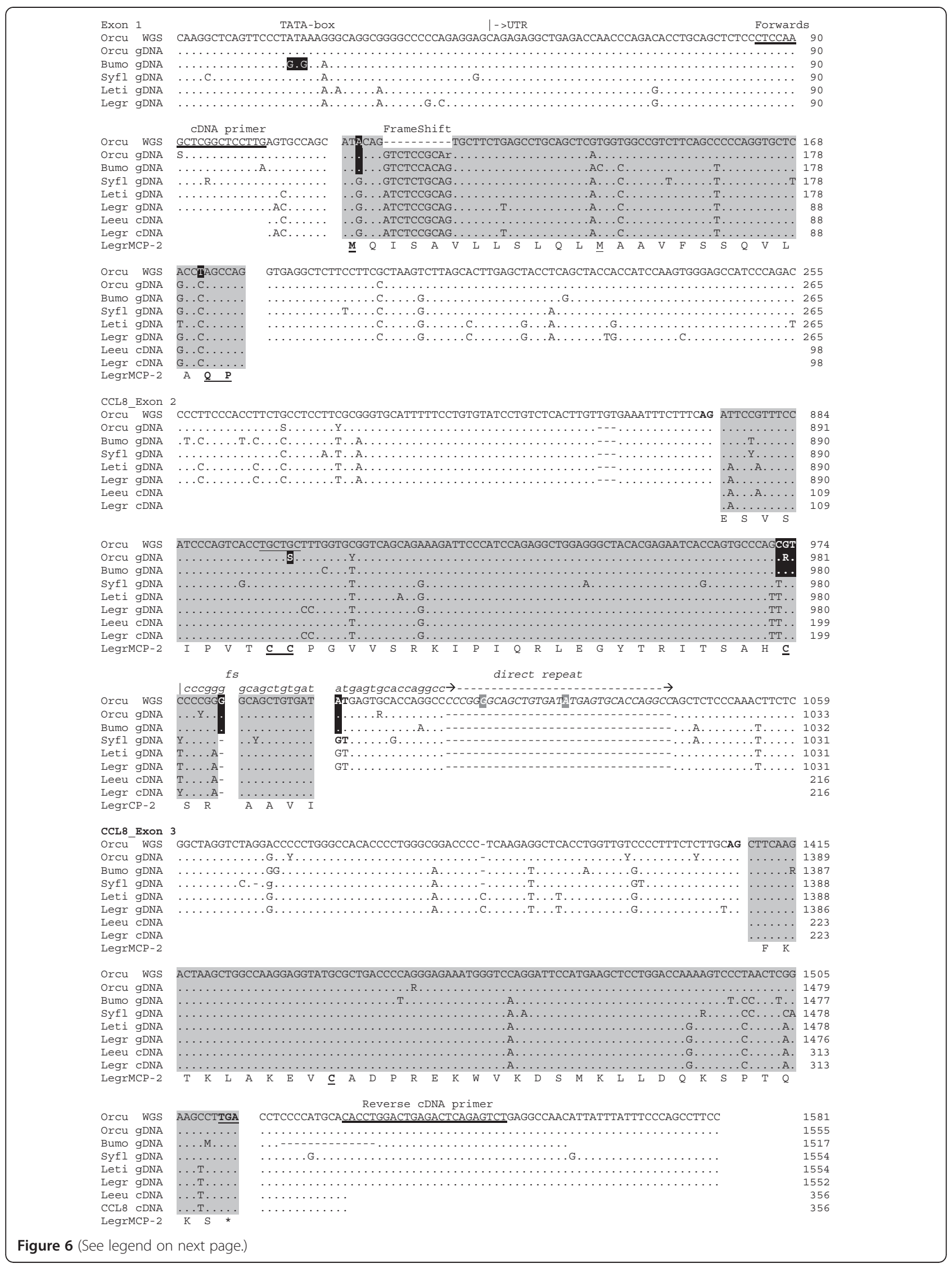


(See figure on previous page.)

Figure 6 Gene variation at the CCL8 locus within and among leporids. PCR products of leporid specimens were obtained using either gDNA or CDNA and are aligned with the CCL8ps sequence of rabbit WGS. Potential Stop and Translation Initiating codons are underlined. The positions of the CDNA primers are bold underlined. 'Orcu CCL8ps' represents the consensus of 11 haplotypes of Oryctolagus cuniculus specimens of both subspecies (O. c. cuniculus and O. c. algirus), after excluding one haplotype that was identical to CCL8ps of WGS (OccTar109allele1) and ignoring singletons (i.e. nucleotide differences observed only once). Occ: Oryctolagus cuniculus; Bumo: Bunolagus monticularis; Syfl: Sylvilagus floridanus; Leti: Lepus timidus; Legr: Lepus granatensis; Leeu: Lepus europaeus. '.': identical to leader sequence; '-': indel. The data shown are limited to the exon containing fractions. An alignment of the entire 1.6Kb gene region is presented in Additional file 7.

exon 1 and of the 33 bp direct repeat at the $5^{\prime}$ region of intron2 of Rabbit CCL8 (Figure 6). It further supports the viewpoint that the two occasional indels occurred after the initial pseudogenization. The Bunolagus CCL8 pseudogene differs however from that of Oryctolagus by the absence of a theoretical 'rescue' initiator codon (ATG->ACG) in exon1, and the loss of the TATA box (TATAAA-> TgTgAA), which Oryctolagus shares with many mammalian CCL8 genes.

\section{MCP-2/CCL8 appears to be functional in Lepus and Sylvilagus species}

The next question was whether the CCL8 gene is also pseudogenized in species of leporid lineages that do not share the CCR5 mutation with rabbit. As mentioned before, these species are also those that are resistant to MYXV. Using the primer sets designed for amplifying the three Rabbit-CCL8ps exons, we found that all haplotypes obtained with two Lepus specimens and three Sylvilagus specimens possess a CCL8 ortholog which does not show any disabling mutations. The CDS consensus sequences are shown in alignment with Rabbit sequences (see Figure 6). The same alignment including the complete UTR's and intron regions can be found in Additional file 7. The usual amino acid numbering of mature MCP-2 protein is shown in the alignment presented in Figure 7.

The functionality of the CCL8 gene was further evaluated by analyzing cDNA obtained with specimens of species Oryctolagus and Lepus. Although the primers were designed according to the Oryctolagus sequence, the expected CCL8 CDS sequences were obtained with both specimens of Lepus but not with cDNA of Oryctolagus. This failure was not due to the quality of the Rabbit cDNA, because successful PCR amplification of CCL7 was obtained using the same cDNA preparation with the appropriate primers (Figure 1). Tissue samples of Sylvilagus specimens were not suited for RNA extraction, but the extensive sequence similarity with Lepus CCL8 predicts correct splicing and gene transcription, which was also confirmed by gene finder software applied to the genomic sequences of both genera.

The Rabbit genome contains only one CCL8-like gene A last question was whether functional CCL8-like genes might exist outside or within the $\mathrm{R}-\mathrm{MCPgb}$ region studied. At least in mouse, cow and elephant the CCL8 genes are indeed duplicated, which, parenthetically, might be a further indication of their relative importance (in mouse they are named CCL12 and CCL8, although CCL12 is more similar to mammalian CCL8; Figure 3). By blasting the (entire) Rabbit WGS database (inclusive the Trace File Archives) with the Rabbit-CCL8 sequences here presented, at the exception of full identity with the actual query, highest similarities were obtained with sequences of the CCL11 and CCL7 genes embedded in the R-MCPgb fragment. It strongly suggests that there is no other CCL8-like gene in the entire genome of the specimen studied in the Rabbit Genome Project.

We can therefore ascertain that the unique ortholog of the mammalian CCL8 gene is pseudogenized in the Old Word leporid genera Oryctolagus and Bunolagus, while potentially functional in Sylvilagus and Lepus species and, at least in Lepus, being correctly transcribed.

\section{Discussion}

We show that both MCP-2/CCL8 and CCR5 were altered in lineage of Oryctolagus and Bunolagus due to apomorphic mutations which did not occur in the lineage comprising species of Sylvilagus and Lepus. It implies that the species known to be reservoirs of MYXV, i.e. S. brasiliensis and S. bachmani, dispose most likely of normal (plesiomorphic) CCR5 and CCL8 genes. Although such deductions are in line with current phylogenetic inference, they might be worthwhile to be verified, as falsification would imply the independent alteration of one or both of these genes in lineages separated in space and time for millions of years. Meanwhile we will assume that the CCR5 and CCL8 genes of the different Sylvilagus species do not differ significantly from those shared by the New World rabbits of this study.

The situation revealed by the presented data might orientate research towards the role of chemokine and their receptors in host species of MYXV and could lead to new insights in processes of parasite-host coadaptation. In mice MCP-2/CCL8 and CXCL12 were found to cooperate to attract hematopoietic progenitors of immune-regulatory dendritic cells [43] while Islam and coworkers [44] describe mouse MCP-2/CCL8 as crucial 


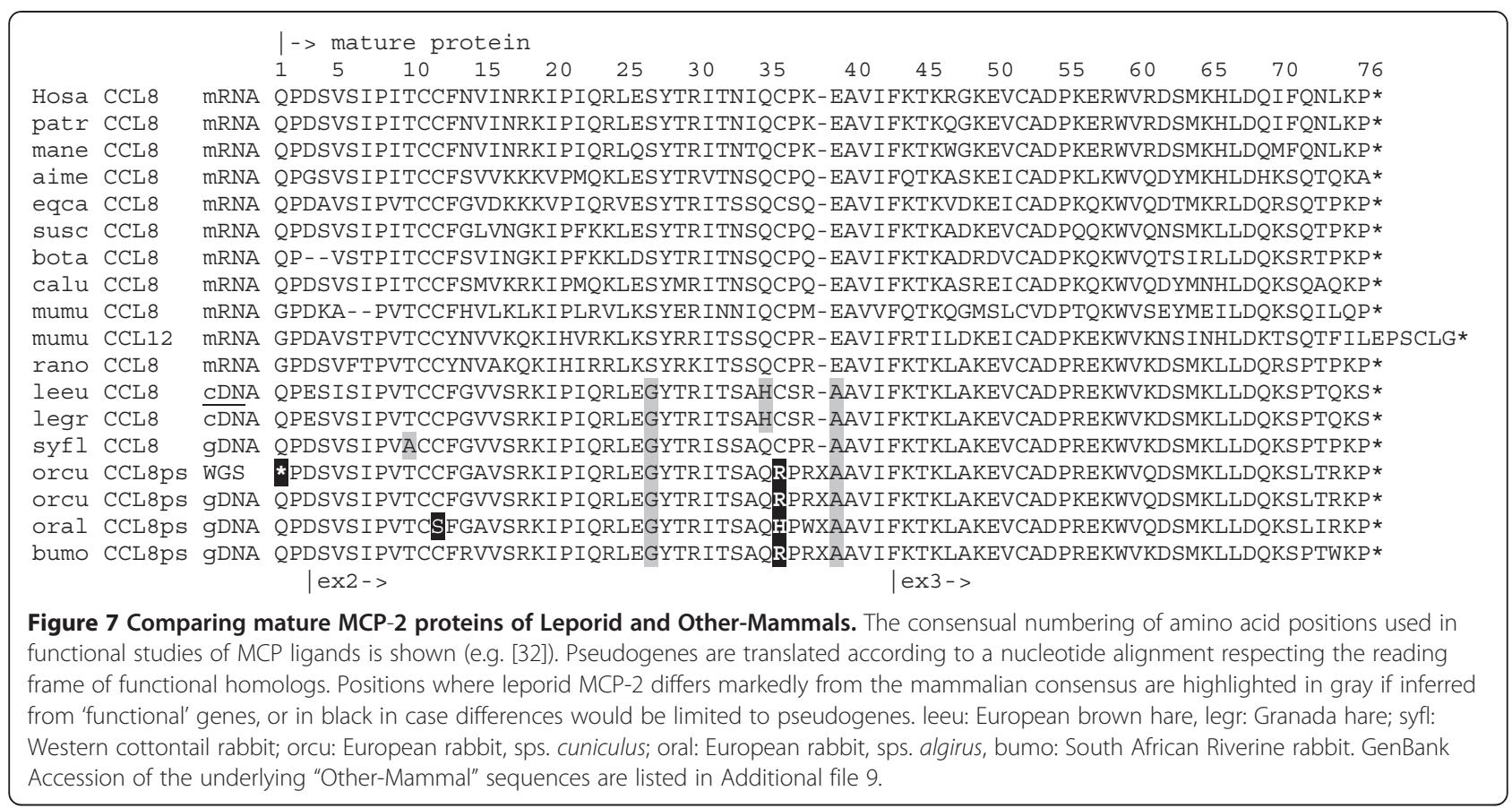

regulator of $\mathrm{T}(\mathrm{h}) 2$ cell homing. In Human, MCP-2 is known to bind to chemokine receptors CCR1, CCR2 and CCR 5 and can act as a potent inhibitor of HIV-1 infectivity [44-46]. More in particular, compared to other chemokines, MCP-2 was found the most efficient inhibitor of the HIV protein gp120 for CCR5 receptor binding $[47,48]$. Studies of the role of MCP chemokines in $\mathrm{Hu}-$ man and Mouse revealed that inflammation is regulated by feedback mechanisms where proteases play an important role [24,33-35]. They act by removing the $\mathrm{N}$ terminal tetra or penta peptide of MCP's which can transform them into MCP antagonists. Different research groups reported that natural occurring posttranslational modified MCP-2/CCL8 products can completely (sic) block the chemotactic effects of intact MCP's and of RANTES/CCL5, and have identified natural MCP-2(6-76) (cf. Figure 7) as a potent and functional CC chemokine inhibitor $[28,33,34]$. These studies have highlighted the role played by MCP-2 products in the subtle agonistantagonist interplay with $\mathrm{CC}$ chemokine receptors, including CCR5.

In this context our data might fuel speculations about possible reasons underlying the permanent loss in Old World rabbits of an important gene function,

Table 2 Species names and their abbreviations, and sample names (inclusive geographic origin), of studied specimens

\begin{tabular}{ll}
\hline Species: & References and sample names: \\
\hline European rabbit: & \\
Oryctolagus c. cuniculus (Occ): & OccTar104, OccTar109, OccAlt104, OccZrg18 (Spain) \\
Oryctolagus c. aligirus (Oca): & OcaPan3, Ocaped1, OcaPed9, OcaMert35 (Portugal), \\
& Oca32 c), OcaHue54 (Spain)
\end{tabular}

South African Riverine rabbit:

Bunolagus monticularis (Bumo):

Bumo, one sample of gDNA donated by Mathew, South Africa.

\section{Cottontail rabbit:}

Sylvilagus floridanus (Syfl) :

Syfl-161, Syfl-162, Syfl-172

Hare:

Lepus timidus (Leti) :

Lepus granadensis (Legr)

Leti2012, Leti2191 (Finland)

Legr2`', Legr6`', Legr2016. Legr2061 (Portugal),

LegrCrd905 (Spain),

Lepus europeus (Leeu) :

Leeu1', Leeu2 ${ }^{\complement}$ (Spain)

c) sources of cDNA, all others were sources of gDNA. 


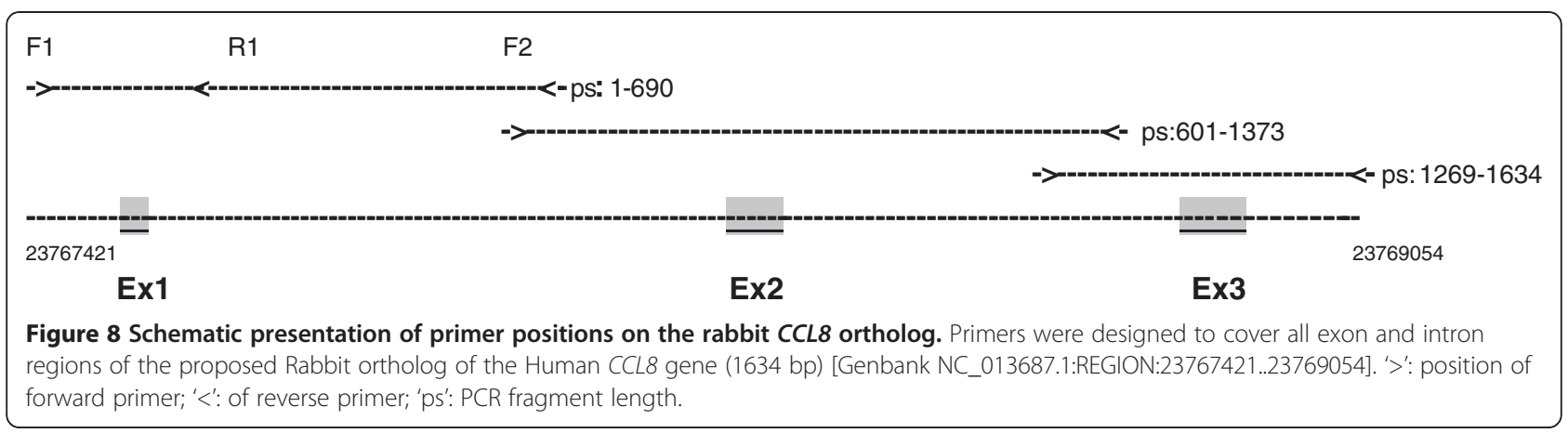

which has been well preserved throughout mammalian evolution ( $c f$. Figures 3 and 4; a CCL8-like gene has also been reported in bony fish [GenBank: BT048349]). One explanation could be that functions of $C C L$ products can be redundant or interchangeable, at least in leporids, which would be at odds with the evolutionary perpetuation of $C C L$ gene identity. More interesting is the hypothesis of a causal link between the appearance within the lineage of Old World rabbits of the alteration at the second external loop of CCR5 on one hand, and the pseudogenization of one of its prime ligands on the other. Both events are highly unusual and none of them did occur in the Sylvilagus-Lepus lineage, nor in any other studied species. Although the argument is somewhat circular - we looked at the CCL8 gene precisely because of the CCR5 alteration it can offer a plausible explication for the knock-out of an otherwise prominent gene function over a period of more than $4 \mathrm{My}$ ( $c f$. Figure 3). If "lost by accident", the CCL8 gene could during this period have been repaired by back-mutations or by gene conversion with one of its neighbors. One might consider that receptor alteration occurred first, making CCL8 either useless or even detrimental, allowing or forcing its permanent pseudogenization. Or on the contrary, the CCL8 gene knock-out, and the consecutive perturbation of CCR5dependent signaling pathways (e.g. due to the loss of a potential (ant)agonist of other CCR5 ligands such as Rantes/CCL5), may have favored structural change at its orphaned target (i.e. at the second external loop of CCR5). Regardless of the scenario, we could be facing an irreversible situation where a "gene knock-out" resulted in a gene "lock-out". Indeed gene repair would not be favored by selection if the recovered ligand can

Table 3 List of primer pairs

\begin{tabular}{|c|c|c|c|c|}
\hline Gene & Exon & Primer name & Sequence & R-MPCgb \\
\hline \multicolumn{5}{|l|}{ gDNA } \\
\hline \multirow[t]{7}{*}{ CCL8 } & ex1 & FwPrCL8e1 & 5' AGCACACGCAGGGTCTTGCT 3' & $47421-47440^{\S}$ \\
\hline & & RvPrCL8e1a & 5' ATGGCTCCCACTTGGATGGC 3' & $47692-47711$ \\
\hline & & RvPrCL8e1b & 5' TCGACCCCGTGGGCTGGTAG 3' & $48091-48110$ \\
\hline & ex2 & FwPrCL8e2a & 5' GCATCCAGCACGGTGGCTGT 3' & $48021-48040$ \\
\hline & & RvPrCL8e2a & 5' GCCAGCCCTTGCTCCTTGGG 3' & $48774-48793$ \\
\hline & ex3 & FwPrCL8e3b & 5' GGCTCCAGGTGCTTCAGCCA 3' & $48659-48678$ \\
\hline & & RvPrCL8e3b & 5'AGTACCCAGGGAAGGCTGGG 3' & $49034-49054$ \\
\hline \multirow[t]{4}{*}{ CCL13 } & ex1 & F1CL13e1 & 5' TTGGCTCTCCCGTGGCAGCA 3' & $72054-72073$ \\
\hline & & R1CL13e1 & 5' GGCCAGCACTATGGCGCAGT 3' & $72537-72556$ \\
\hline & & F9CL13e1 & 5' AGGCAGCAAGCATGGGAGCG 3' & $71722-71741$ \\
\hline & & R9CL13e1 & 5' GGGCCCTTTGGCTTAGAAGGCG 3' & $72226-72206$ \\
\hline \multicolumn{5}{|l|}{ cDNA } \\
\hline \multirow[t]{2}{*}{ CCL8 } & CDS & FwCCL8_CDS & 5' CTCCAAGCTCGGCTCCTTG 3' & $47548-47566$ \\
\hline & & RvCCL8_CDS & 5' ACTCTGAGTCTCAGTCCAGGTG 3' & 48990-49011 \\
\hline \multirow[t]{2}{*}{ CCL7 } & CDS & FwCCL7_CDS & 5' AGGCTGAGGCCAGCACAGGA 3' & $13720-13739$ \\
\hline & & RvCCL7_CDS & $5^{\prime}$ TCCTCCCCCATGCCAGTGCA $3^{\prime}$ & $11541-11560$ \\
\hline
\end{tabular}

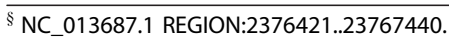


no longer recognize its receptor (why repair the key if the lock has changed). It might therefore be interesting to know to what extent, if at all, the receptor mutation impairs the affinity of the different CCR5 ligands.

A further question beyond our competence is whether, when, and in which cellular environment CCL8 is expressed in Sylvilagus during MYXV infection and how, at the event, it contributes to the clearance of infected lymphocytes. In this context it might be interesting to mention that MCP-2 expression was down regulated in human HIV infected brain cells by miRNA146a [49], a microRNA which we found to be present in Rabbit (the miRNA146a sequences are identical among Human and Rabbit and are localized in same chromosomal region; WvdL unpublished observations).

\section{Conclusions}

The large number of host-specific immunodulatory proteins encoded by MYXV implies multiple levels of elaborate interactions between the virus and its natural host which can be the outcome of thousands of years of co-adaptive evolution. Identifying the constituents of this interplay remains a huge challenge, as host factors involved can be even more numerous. It might therefore be worthwhile to consider that the knock-out of a single host factor could severely affect this virus-host equilibrium. Given that monocyte chemotactic proteins control patterns of leukocyte migration, which in turn govern the outcome of MYXV infection in rabbits, the observation of a factual correlation between the near absence of MYXV virulence and the concurring presence of a functional MCP-2/CCL8 and an intact' CCR5 gene, could promote studies on the role played by this particular chemokine ligand-receptor interaction in keeping Myxoma virus under control.

\section{Methods}

Tissue samples specimens of leporid species belonging to genera Oryctolagus, Lepus and Sylvilagus were provided by CIBIO Lagomorph Tissue Collection maintained by Paulo C. Alves (CIBIO, Vairão, Portugal; pcalves@mail.icav.up.pt). Species and sample names are listed in Table 2. All samples are from wild populations.

\section{gDNA}

For the genomic DNA extraction of Oryctolagus (9 specimens) and Lepus (5 specimen) we used liver tissues preserved at $-20^{\circ} \mathrm{C}$ in RNA stabilizing medium. We were privileged by the generous gift of Bunolagus gDNA prepared by Conrad Mathee. For Sylvilagus we only disposed of blood clots with mRNA not suitable for cDNA synthesis. Genomic DNA was extracted using the EasySpin Genomic DNA Minipreps Tissue Kit (Citomed) according to manufacturer's instructions.

\section{CDNA}

Total RNA was prepared for one wild rabbit (Oryctolagus cuniculus algirus: Oca32), and four hares (genus Lepus). The hare specimens represent two species: Iberian hare (Lepus granatensis: Legr2, Legr6) and European brown hare (Lepus europaeus: Leeu1, Leeu2). RNA was extracted using the guanidinium thiocyanate-phenol-chloroform extraction method (TRIzol) according to manufacturer's instructions (Molecular Research Center, Inc., Cincinnati, $\mathrm{OH}$, USA). Next, first strand cDNA was prepared from $5 \mu \mathrm{g}$ of RNA and synthesized using oligo (dT) primers [50]. The putative CCL8 and CCL7 transcripts were PCRamplified using a primer set located in the UTR regions.

\section{PCR}

Primers were designed according to the R-MCPgb fragment of the Rabbit chromosome 19 [GenBank: NC_013687.1_REGION:23720000..23798000], using the online software Primer-Blast provided by NCBI [51]. For amplification of genomic CCL8, primers were designed separately for each of the three exons, in a way covering all coding and intron regions (see Figure 8). Primer pairs are listed in Table 3. PCR methods were standard. Details are given in Additional file 8. For the sequencing reactions we used ABI PRISM BigDye Terminator v3.1 Cycle Sequencing Kit and protocols were followed according to the manufactures. The sequencing reactions were cleaned with Sephadex ${ }^{\mathrm{m}}$ from GE Healthcare Life Sciences. Sequencing was performed on an ABI PRISM 310 Genetic Analyser (PE Applied Biosystems). PCR products were sequenced in both directions.

\section{Source of data}

All sequence data except those produced in this study were obtained from GenBank database of the NCBI platform [52] or Ensembl [53]. The GenBank accession numbers of nucleotide sequences used in this study are listed in Additional file 9. Sequences produced in this study were submitted to GenBank and the accession numbers are listed in Table 4.

\section{Sequence analysis}

Alignments were done using the online software "Align" provided by the NCBI site in combination with online software Dialign [54] and Clustal W as incorporated in the MEGA5 package [36] and improved by visual corrections using BioEdit [55]. Phylogenetic analysis shown was conducted using Maximum Likelihood method provided in MEGA5 [36]. The probability of gene transcription of undocumented CCL orthologs was evaluated with GenScan [29]. 
Table 4 GenBank accessions of novel nucleotide sequences

\begin{tabular}{|c|c|c|}
\hline Description & GenBank Name & GB Accession \\
\hline Legr_CCL8_cDNA & CCL8_Legr2 & JX000247 \\
\hline Leeu_CCL8_cDNA & CCL8_Leeu1 & JX000248 \\
\hline Legr_CCL8_cDNA & CCL8_Legr6 & JX000249 \\
\hline Leeu_CCL7_cDNA & CCL7_Leeu2 & JX000250 \\
\hline Legr_CCL7_cDNA & CCL7_Legr6 & JX000251 \\
\hline Occ_CCL7_cDNA & CCL7_Occ32 & $J \times 000252$ \\
\hline Occ_CCL8_gDNA & CCL8gDNA_Occ_Tar109_1 & JX000253 \\
\hline Occ_CCL8_gDNA & CCL8gDNA_Occ_Tar109_2 & JX000254 \\
\hline Occ_CCL8_gDNA & CCL8gDNA_Occ_Alt104_1 & JX000255 \\
\hline Occ_CCL8_gDNA & CCL8gDNA_Occ_Alt104_2 & JX000256 \\
\hline Occ_CCL8_gDNA & CCL8gDNA_Occ_Tar102_1 & JX000257 \\
\hline Occ_CCL8_gDNA & CCL8gDNA_Occ_Tar102_2 & JX000258 \\
\hline Occ_CCL8_gDNA & CCL8gDNA_Occ_Zrg18_1 & JX000259 \\
\hline Oca_CCL8_gDNA & CCL8gDNA_Occ_Zrg18_2 & JX000260 \\
\hline Oca_CCL8_gDNA & CCL8gDNA_Oca_Pan3_1 & JX000261 \\
\hline Oca_CCL8_gDNA & CCL8gDNA_Oca_Pan3_2 & JX000262 \\
\hline Oca_CCL8_gDNA & CCL8gDNA_Oca_Ped1 & JX000263 \\
\hline Oca_CCL8_gDNA & CCL8gDNA_Oca_Ped9_1 & JX000264 \\
\hline Oca_CCL8_gDNA & CCL8gDNA_Oca_Ped9_2 & JX000265 \\
\hline Oca_CCL8_gDNA & CCL8gDNA_Oca_Mert35_1 & JX000266 \\
\hline Oca_CCL8_gDNA & CCL8gDNA_Oca_Mert35_2 & JX000267 \\
\hline Oca_CCL8_gDNA & CCL8gDNA_Oca_Hue54 & JX000268 \\
\hline Bumo_CCL8_gDNA & Bumo_CCL8 & JX000276 \\
\hline Legr_CCL8_gDNA & Legr_CCL8 & JX000277 \\
\hline Syfl_CCL8_gDNA & Syfl_CCL8_1 & JX000279 \\
\hline Syfl_CCL8_gDNA & Syfl_CCL8_2 & JX000280 \\
\hline Oca_CCL13_exon1_gDNA & Oca_Pan3x_CCL13ex1 & JX020976 \\
\hline Oca_CCL13_exon1_gDNA & Oca_Pan3y_CCL13ex1 & JX020977 \\
\hline Oca_CCL13_exon1_gDNA & Oca_Ped1_CCL13ex1 & JX020978 \\
\hline Oca_CCL13_exon1_gDNA & Oca_Ped9_CCL13ex1 & JX020979 \\
\hline Leti_CCL13_exon1_gDNA & Leti_2061_CCL13ex1 & JX020980 \\
\hline Syfl_CCL13_exon1_gDNA & Syfl_161_CCL13ex1 & JX020981 \\
\hline Syfl_CCL13_exon1_gDNA & Syfl_162_CCL13ex1 & JX020982 \\
\hline Syfl_CCL13_exon1_gDNA & Syfl_171x_CCL13ex1 & JX020983 \\
\hline Syfl_CCL13_exon1_gDNA & Syfl_171y_CCL13ex1 & JX020984 \\
\hline Syfl_CCL13_exon1_gDNA & Syfl_176_CCL13ex1 & JX020985 \\
\hline
\end{tabular}

Sequences were obtained by PCR using either genomic DNA (gDNA) or reverse transcribed mRNA (cDNA). Species names are indicated by abbreviations (Legr: Lepus granatensis; Leeu: Lepus europaeus; Leti: Lepus timidus; Bumo: Bunolagus monticularis; Syfl: Sylvilagus floridanus; Oc: Orytolagus cuniculus). The two subspecies of Oryctolagus cuniculus are distinguished (Occ: $O$. cuniculus cuniculus; Oca: $O$. cuniculus algirus). Extensions ( $x$ and $y$ ) refer to reproducible sequence ambiguities in PCR products obtained from a same individual that can be explained by allelic variation. Legr_CCL8 is a consensus sequence of Legr2016 and Legr2061;

Syfl_CCL8_1 and_2 are two putative alleles inferred from sequences obtained with Syfl-161, -162, -171, -172, -176.

\section{Endnotes}

a) MCP-2/CCL8 and similar. Read: either the Monocyte chemotactic protein type 2 encoded by the gene $C C L 8$, or the CCL8 gene encoding the $\mathrm{MCP}-2$ protein, depending on context. Maintaining the MCP nomenclature for proteins is preferred because used in studies of chemokines function.

b) Rabbit and rabbit: Species name are capitalized when used to avoid irrelevant repetitions of scientific names (European rabbit or Oryctolagus cuniculus). Thus "Rabbit genome" or "Rabbit 
sequences" but "rabbits were collected". By analogy we write Human, Cottontail rabbit etc. depending on context.

\section{Additional files}

\section{Additional file 1: GenBank Features file for Rabbit NC_013687 REGION: $23720000 . .23798000$.}

Additional file 2: Alignment of Oryctolagus cuniculus and Homo sapiens WGS sequences: identifying rabbit ortholog of human CCL7.

Additional file 3: Alignment of Oryctolagus cuniculus and Homo sapiens WGS sequences: identifying the rabbit ortholog of human CCL8.

Additional file 4: Alignment of Oryctolagus cuniculus and Homo sapiens WGS sequences: identifying rabbit ortholog of human CCL13.

Additional file 5: Alignment of MCP encoding regions of rabbit and human in Fasta format.

Additional file 6: Rabbit CCL13 ortholog named 'CCL8' or 'CCL7'.

Additional file 7: Nucleotide variation at CCL8 genes within and among leporid species.

Additional file 8: Detailed PCR procedures.

Additional file 9: Genbank Accessions and Links of MCP-Eotaxin mRNA sequences of Placental Mammals used or consulted.

\section{Abbreviations}

MIP: Macrophage inflammatory proteins; MCP: Monocyte chemotactic proteins; R-MCPgb: Rabbit MCP-Eotaxin WGS fragment [Genbank: NC_013687 REGION: 23720000.23798000]; MYXV: Myxoma virus; MHC-II: Major Histocompability Complex Class 2; HIV: Human Immunodeficiency Virus; CCL: CC chemokine ligand; CCR: CC chemokine receptor; WGS: Whole Genome Sequence; i.e.: In extenso, more in detail; e.g.: Exempli gratia, for example; cf: Confer; indel: Insert or deletion in sequence comparisons.

\section{Competing interests}

The authors declare that they have no competing interests.

\section{Authors' contribution}

WvdL conceived the study and its design and carried out the literature research, data mining and analysis, drafting and editing of the manuscript. The most important findings of present report were nevertheless produced by SA and ALM, who provided the new data which are the core of the paper. SA did the PCR amplifications and sequencing, revealing the existence of a potentially functional CCL8 gene in Lepus and Sylvilagus species. ALM contribution was the CDNA work, putting the corner stone to this study by showing that in these species the CCL8 gene is transcribed. PJE is the leader and JA one of the most inspiring members of the CIBIO Evolutionary Immunogenetic Group, and played an important role in coordinating and supporting the work of ALM and SA, and by critical commenting and stimulating discussion of the manuscript.

\section{Acknowledgments}

We want to thank Paulo Alves and his staff for the maintenance of the Lagomorph tissue collection and Conrad Matthee for providing the sample of South-African Riverine rabbit. The Portuguese Foundation for Science and Technology supported the doctoral fellowship of ALM (SFRH/BD/48566/ 2008), the post-doctoral fellowships of JA (SFRH/BPD/73512/2010) and PJE (SFRH/BPD/27021/2006) and the project (PTDC/BIA-BEC/103158/2008).

\section{Author details}

${ }^{1} \mathrm{CIBIO}-U \mathrm{P}$, Centro de Investigação em Biodiversidade e Recursos Genéticos, Campus Agrário de Vairão, Universidade do Porto, Vairão 4485-661, Portugal. ${ }^{2}$ Departamento de Zoologia e Antropologia, Faculdade de Ciências, Universidade do Porto, Porto 4169-007, Portugal. ${ }^{3}$ Department of Microbiology and Immunology, Stritch School of Medicine, Loyola University Chicago, Maywood, IL 60153, USA. ${ }^{4}$ INSERM U892 - Institut de Biologie
Equipe 5, Nantes, Cedex 01 44007, France. ${ }^{5}$ Centro de Investigação em Tecnologias da Saúde, IPSN, CESPU, Gandra 4585-116, Portugal.

Received: 6 February 2012 Accepted: 11 July 2012 Published: 15 August 2012

\section{References}

1. Lopez-Martinez N: Revision sistematica y biostratigrafica de los lagomorphos (Mammalia) del neogeno y cuaternario de España. Disputacion General de Aragon: Memorias del Museo Paleontologico de la Universidad de Zaragoza; 1989.

2. Chapman JA, Flux JEC: Rabbits, hares and pikas: status survey and conservation action plan. IUCN/SSC Lagomorph Specialist Group (ed.). Oxford UK: Information Press; 1990

3. Rougeot J: Origin et histoire du lapin. Ethnozootechnie 1981, 27:1-9.

4. Flux JEC: World distribution. In The European rabbit: The history of a successful colonizer. Edited by Thomson HV, King CM. Oxford: Oxford Science Publications; 1994:8-21.

5. Callou C: Modifications de l'aire de répartition du Lapin (Oryctolagus cuniculus) en France et en Espagne, du Pléistocène à l'époque actuelle État de la question. Anthropozoologica 1995, 21:95-114.

6. Monnerot M, Vigne JD, Biju-Duval C, Casane D, Callou C, Hardy C, Mougel F, Soriguer R, Dennebouy N, Mounolou JC: Rabbit and man: genetic and historic approach. Genet Sel Evol 1994, 26:167-187.

7. Fenner F: Myxomatosis. Br Med Bull 1959, 15:240-245.

8. Hyde RR, Gardner E: Infectious myxoma of rabbits. Am J Epidemiol 1933, 17:446-46

9. Regnery DC, Marshall ID: Studies in the epidemiology of myxomatosis in California IV: the susceptibility of six leporid species to Californian myxoma virus and the relative infectivity of their tumors for mosquitoes. Am J Epidemiol 1971, 94:508-513.

10. Best SM, Collins SV, Kerr PJ: Coevolution of host and virus: cellular localization of virus in myxoma virus infection of resistant and susceptible European rabbits. Virology 2000, 277:76-91.

11. Zúniiga MC: Lessons in détente or know thy host: the immunomodulatory gene products of myxoma virus. J Biosci 2003, 28:273-285.

12. Stanford MM, Werden SJ, McFadden G: Myxoma virus in the European rabbit: interactions between the virus and its susceptible host. Vet Res 2007, 38:299-318.

13. McFadden G, Graham K, Ellison K, Barry M, Macen J, Schreiber M, Mossman K, Nash P, Lalani A, Everett H: Interruption of cytokine networks by poxviruses: lessons from myxoma virus. J Leukoc Biol 1995, 57:731-738.

14. Ransohoff RM: Chemokines and chemokine receptors: standing at the crossroads of immunobiology and neurobiology. Immunity 2009, 31:711-721.

15. Liu J, Wennier S, McFadden G: The immunoregulatory properties of oncolytic myxoma virus and their implications in therapeutics. Microbes Infect 2010, 12:1144-1152.

16. Spiesschaert B, McFadden G, Hermans K, Hans Nauwynck H, Van de Walle GR: The current status and future directions of myxoma virus, a master in immune evasion. Vet Res 2011, 42:76:1-18.

17. Lalani AS, Masters J, Zeng W, Barrett J, Pannu R, Everett H, Arendt CW, McFadden G: Use of chemokine receptors by poxviruses. Science 1999, 286:1968-1971.

18. Masters J, Hinek AA, Uddin S, Platanias LC, Zeng W, McFadden G, Fish EN: Poxvirus infection rapidly activates tyrosine kinase signal transduction. J Biol Chem 2001, 276:48371-48375.

19. Johnston JB, Johnston JB, Barrett JW, Chang W, Chung CS, Zeng W, Masters J, Mann M, Wang G, McFadden G: Role of serine-threonine kinase PAK-1 in Myxoma virus replication. J Virol 2003, 77:5877-5888.

20. Carmo CR, Esteves PJ, Ferrand N, van der Loo W: Genetic variation at chemokine receptor CCR5 in leporids: alteration at the 2 nd extracellular domain by gene conversion with CCR2 in Oryctolagus, but not in Sylvilagus and Lepus species. Immunogenetics 2006, 58:494-501.

21. Abrantes J, Carmo CR, Matthee CA, Yamada F, van der Loo W, Esteves P. A shared unusual genetic change at the chemokine receptor type 5 between Oryctolagus, Bunolagus and Pentalagus. Conserv Genet 2011. 12:325-330.

22. Nomiyama $\mathrm{H}$, Osada $\mathrm{N}$, Yoshie O: The evolution of mammalian chemokine genes. Cytokine Growth Factor Rev 2010, 21:253-262. 
23. Eli and Edythe L, Broad Institute of Harvard and MIT: Rabbit Genome Project. http://www.broadinstitute.org/scientific-community/science/projects/ mammals-models/rabbit/rabbit-genome-project.

24. Howard MZ, Galligan CL: An expanding appreciation of the role chemokine receptors play in cancer progression. Curr Pharm Des 2004, 10:2377-2389.

25. Loetscher P, Seitz M, Clark-Lewis I, Baggiolini M, Moser B: Monocyte chemotactic proteins MCP-1, MCP-2, and MCP-3 are major attractants for human CD4+ and CD8+ T lymphocytes. FASEB J 1994, 8:1055-1106.

26. Van Coillie E, Proost P, Van Aelst I, Struyf S, Polfliet M, De Meester I, Harvey DJ, Van Damme J, Opdenakker G: Functional comparison of two human monocyte chemotactic protein-2 isoforms, role of the amino-terminal pyroglutamic acid and processing by cd26/dipeptidyl peptidase IV. Biochemistry 1998, 37:12672-12680.

27. Hellier S, Frodsham AJ, Hennig BJW, Klenerman P, Knapp S, Ramaley P, Satsangi J, Wright M, Zhang L, Thomas HC, Thursz M, Hill AVS: Association of genetic variants of the chemokine receptor CCR5 and its ligands, RANTES and MCP-2, with outcome of HCV infection. Hepatology 2003, 38:1468-1476

28. Struyf S, Proost P, Vandercappellen J, Dempe S, Noyens B, Nelissen S, Gouwy M, Locati M, Opdenakker G, Dinsart C: Synergistic up-regulation of MCP-2/CCL8 activity is counteracted by chemokine cleavage, limiting its inflammatory and anti-tumoral effects. Eur J Immunol 2009, 39:843-857.

29. Burge C, Karlin S: Prediction of complete gene structures in human genomic DNA. J Mol Biol 1997, 68:78-94. http://genes.mit.edu/GENSCAN.html.

30. Proost $P$, Wuyts A, Van Damme J: Human monocyte chemotactic proteins-2 and -3 : structural and functional comparison with MCP-1. J Leukoc Biol 1996, 59:67-74.

31. Yamamoto N, Tanabe Y, Okamoto R, Dawson PE, Kajihara K: Chemical synthesis of a glycoprotein having an intact human complex-type sialyloligosaccharide under the Boc and Fmoc synthetic strategies. J Am Chem Soc 2008, 130:501-510

32. Proost $P$, Struyf $S$, Wuyts A, Menten $P$, De Meester I, Lambeir AM, Scharpé $S$, Schols D, De Clercq E, Van Damme J: Isolation and identification of naturally modified C-C chemokinesMCP-1, MCP-2 and RANTES: effects of posttranslation modifications on receptor usage, chemotactic and anti-HIV-1 activity. Eur CytokineNetw 1998, 9:73-75.

33. Proost $P$, Struyf $S$, Couvreur M, Lenaerts JP, Conings R, Menten $P$, Verhaert $P$, Wuyts A, Van Damme J: Posttranslational modifications affect the activity of the human monocyte chemotactic proteins MCP-1 and MCP-2: identification of MCP-2 (6-76) as a natural chemokine inhibitor. J Immunol 1998, 160:4034-4041.

34. McQuibban GA, Gong JH, Wong JP, Wallace JL, Clark-Lewis I, Overall M: Matrix metalloproteinase processing of monocyte chemoattractant proteins generates CC chemokine receptor antagonists with antiinflammatory properties in vivo. Blood 2002, 100:1160-1167.

35. Dean RA, Cox JH, Bellac CL, Doucet A, Starr AE, Overall CM: Macrophagespecific metalloelastase (MMP-12) truncates and inactivates $\mathrm{ELR}^{+} \mathrm{CXC}$ chemokines and generates $\mathrm{CCL} 2,-7,-8$, and -13 antagonists: potential role of the macrophage in terminating polymorphonuclear leukocyte influx. Blood 2008, 112:3455-3464.

36. Tamura K, Dudley J, Nei M, Kumar S: MEGA4: Molecular Evolutionary Genetics Analysis (MEGA) software version 4.0. Mol Biol Evol 2007, 24:1596-1599. http://www.megasoftware.net/.

37. Blaszczyk J, Coillie EV, Proost P, Damme JV, Opdenakker G, Bujacz GD, Wang $\mathrm{JM}, \mathrm{Ji}$ X: Complete crystal structure of monocyte chemotactic protein-2, a CC chemokine that interacts with multiple receptors. Biochemistry 2000, 39:14075-14081.

38. van der Loo W, Ferrand N, Soriguer RC: Estimation of gene diversity at the $b$ locus of the constant region of the immunoglobulin light chain in natural populations of European rabbit (Oryctolagus cuniculus) in Portugal, Andalusia and on the Azorean Islands. Genetics 1991, 127:789-799.

39. Branco M, Ferrand N, Monnerot M: Phylogeography of the European rabbit (Oryctolagus cuniculus) in the Iberian Peninsula inferred from RFLP analysis of the cytochrome b gene. Heredity 2000, 85:307-317.

40. Biju-Duval C, Ennafaa H, Dennebouy N, Monnerot M, Mignotte F, Soriguer R, El Gaied A, El Hili A, Mounolou JC: Mitochondrial DNA evolution in lagomorphs: origin of systematic heteroplasmy and organization of diversity in European rabbits. J Molec Evol 1991, 33:92-102.

41. Geraldes A, Ferrand N, Nachman N: Contrasting patterns of introgression at $\mathrm{X}$ linked loci across the hybrid zone between subspecies of the European rabbit (Oryctolagus cuniculus). Genetics 2006, 173:919-933.
42. Matthee CA, van Vuuren BJ, Bell D, Robinson TJ: A molecular supermatrix of the rabbits and hares (Leporidae) allows for the identification of five intercontinental exchanges during the Miocene. Syst Bio/ 2004, 53:433-447.

43. Nguyen Hoang AT, Liu H, Juaréz J, Aziz N, Kaye PM, Svensson M: Stromal cell derived CXCL12 and CCL8 cooperate to support increased development of regulatory dendritic cells following Leishmania infection. J Immunol 2010, 185:2360-2371.

44. Islam SA, Chang DS, Colvin RA, Byrne MH, McCully ML, Moser B, Lira SA, Charo IF, Luster AD: Mouse CCL8, a CCR8 agonist, promotes atopic dermatitis by recruiting IL-5 ${ }^{+} \mathrm{T}_{\mathrm{H}} 2$ cells. Nat Immunol 2011, 12:167-177.

45. Moser B, Wolf M, Walz A, Loetscher P: Chemokines: multiple levels of leukocyte migration control. Trends Immunol 2004, 25:75-84.

46. D'Souza P, Harden V: Chemokines and HIV-1 second receptors. Nat Med 1996, 2:1293-1300

47. Premack BA, Schall TJ: Chemokine receptors: gateways to inflammation and infection. Nat Med 1996, 2:1174-1178.

48. Blanpain C, Migeotte I, Lee B, Vakili J, Doranz BJ, Govaerts C, Vassart G, Doms RW, Parmentier M: CCR5 binds multiple CC-chemokines: MCP-3 acts as a natural antagonist. Blood 1999, 94:1899-1905.

49. Rom S, Rom I, Passiatore G, Pacifici M, Radhakrishnan S, Del Valle L, Piña-Oviedo S, Khalili K, Eletto D, Peruzzi F: CCL8/MCP-2 is a target for mir-146a in HIV-1-infected human microglial cells. FASEB J 2010, 24:2292-2300.

50. Krug MS, Berger SL: First strand cDNA synthesis primed with oligo (dT). Methods Enzymol 1987, 152:316-320.

51. Rozen S, Skaletsky HJ: Primer3 on the WWW for general users and for biologist programmers. In Bioinformatics Methods and Protocols: Methods in Molecular Biology. Edited by Krawetz S, Misener S. Totowa, NJ: Humana Press; 2000:365-386. http://www.ncbi.nlm.nih.gov/tools/primer blast.

52. Benson DA, Karsch-Mizrachi I, Lipman DJ, Ostell J, Sayers EW: GenBank ${ }^{\circledR}$. Nucleic Acids Res 2011, 39:D32-D37.

53. Flicek P, Amode MR, Barrell D, Beal K, Brent S, Chen Y, Clapham P, Coates G, Fairley S, Fitzgerald S, Gordon L, Hendrix M, Hourlier T, Johnson N, Kähäri A, Keefe D, Keenan S, Kinsella R, Kokocinski F, Kulesha E, Larsson P, Longden I, McLaren W, Overduin B, Pritchard B, Riat HS, Rios D, Ritchie GR, Ruffier M, Schuster M, Sobral D, Spudich G, Tang YA, Trevanion S, Vandrovcova J, Vilella AJ, White S, Wilder SP, Zadissa A, Zamora J, Aken BL, Birney E, Cunningham F, Dunham I, Durbin R, Fernández-Suarez XM, Herrero J, Hubbard TJ, Parker A, Proctor G, Vogel J, Searle SM: Ensembl 2011. Nud Acids Res 2011, 39(Database issue):D800-D806. http://www.ensembl.org/ index.html.

54. Brudno M, Steinkamp R, Morgenstern B: The CHAOS/DIALIGN WWW server for multiple alignment of genomic sequences. Nucl Acids Res 2004, 32: W41-W44. http://dialign.gobics.de.

55. Hall T: Bioedit. v7th edition. 2011,1-3. http://www.mbio.ncsu.edu/bioedit/bioedit. html.

doi:10.1186/1471-2156-13-72

Cite this article as: van der Loo et al.: Pseudogenization of the MCP-2/ CCL8 chemokine gene in European rabbit (genus Oryctolagus), but not in species of Cottontail rabbit (Sylvilagus) and Hare (Lepus). BMC Genetics 2012 13:72.

\section{Submit your next manuscript to BioMed Central and take full advantage of:}

- Convenient online submission

- Thorough peer review

- No space constraints or color figure charges

- Immediate publication on acceptance

- Inclusion in PubMed, CAS, Scopus and Google Scholar

- Research which is freely available for redistribution 